\title{
The elderly and their medication: understanding and compliance in a family practice
}

\author{
P Blenkiron
}

\begin{abstract}
Summary
Eighty patients aged 75 years and over were interviewed in the surgery or at home to assess their level of knowledge, degree of compliance, and problems with their medicines. Regular medication was prescribed to 59 patients, who took a total of 206 drugs. The correct purpose of medication was stated in $72 \%$ of cases, the dosage regimen recalled accurately for $75 \%$, and the correct name given for $64 \%$ of drugs. The elderly rated their compliance as 'good' (never miss doses) for $77 \%$ of drugs prescribed. This correlated poorly for individual patients with the level of correct compliance as assessed on computer records of repeat prescriptions, which nevertheless was accurate for $80 \%$ of medicines taken. A significant difficulty for the elderly was the removal of tops from medicine containers, occurring in 18 cases ( $31 \%$ patients), including half of those taking analgesics or nonsteroidal anti-inflammatory drugs. The widespread, legally enforced, use of childresistant containers for the elderly frequently seems inappropriate. Further improvements in comprehension and compliance may occur with regular explanation and rationalisation of medication by the family doctor, when visiting the elderly at home.
\end{abstract}

Keywords: elderly, compliance

As the proportion of elderly in the general population has expanded, so has the importance of medicines taken by them. Approximately $70-80 \%$ of those aged over 75 years are taking prescribed drugs, mostly as long-term repeats. ${ }^{1-3}$ This represents more than three times as many drugs as in the general population. ${ }^{4}$ Department of Health data show a $27 \%$ increase between 1977 and 1985 in the average number of prescribed drugs taken by each person of pensionable age. ${ }^{2}$

The likelihood of adverse drug reactions is compounded in the elderly by polypharmacy, ${ }^{6}$ mental impairment, often multiple diseases, and important physiological changes such as decreasing renal function. ${ }^{5-7}$ Proper understanding and compliance regarding medication is central to the avoidance of drug-related problems. Whilst some research suggests that the majority of elderly patients can accurately repeat dosage instructions, ${ }^{4}$ in practice, up to
$75 \%$ make errors in compliance, a quarter of which are potentially serious. ${ }^{5}$ As a Royal College of Physicians report on this subject has commented, ${ }^{5}$ compliance is related to many factors, including knowledge of the medication, ${ }^{8,9}$ memory, patient expectations and satisfaction, and rapport between doctor and patient. In addition, impairment of eyesight and manual dexterity can make it difficult for old people to read labels or open medicines, especially those in child-resistant containers. ${ }^{10}$

Against this background, this study aimed to assess, by direct questioning of the patient, the extent and nature of prescribing to those aged 75 years and over, in one rural dispensing practice. Patient compliance and understanding, difficulties with medication, and coping strategies to overcome perceived problems were all examined in detail. It was hoped that a greater knowledge of drug-taking by the elderly would provide valuable feedback on current standards of care, and suggest practical areas of improvement within the practice.

\section{Methods}

Eighty patients were interviewed with their consent by the author, a trainee working in the practice. Patients were selected from one of three different sources: those attending for ordinary consultation at the surgery (17 cases); those routinely visited for chronic stable conditions at home (16 cases); those visited at home after random selection of their name from the files (47 cases).

Acutely ill patients and those in nursing or residential homes were excluded. In each case the name, address and date of birth were checked against the general practice records, and it was noted whether the patient was living alone, with their spouse or other family member. Each patient was asked to show all medicines taken where possible, including those drugs not prescribed. Questions were asked about the name and purpose of each drug, and the number/timing of doses taken each day. The patient was asked to read the label instructions (with spectacles where required) to assess legibility. Enquiry was made about difficulties encountered in medicinetaking, and any coping strategies used by the patient to remind them to take doses. Other patient comments and suggestions on possible improvements in their drug administration were sought in each case. For those patients whose knowledge about their medicine was not perfect, appropriate explanations were given 


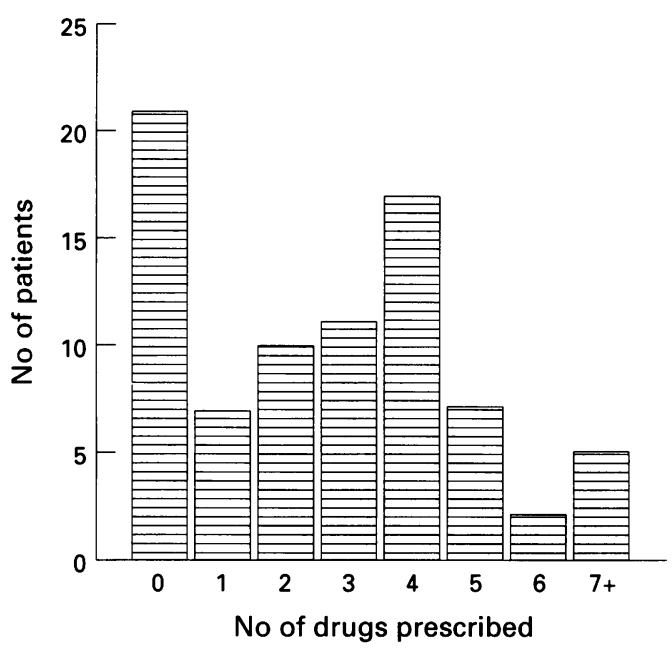

Figure Number of drugs taken by elderly patients

and a previously evaluated brief mental test score $^{1}$ applied to assess orientation (box 1).

Compliance may be defined as "the extent to which the patient's behaviour coincides with medical advice". ${ }^{7}$ No single method of assessing compliance is perfect. ${ }^{11}$ One acceptable option is to question the patient, although this can underestimate poor compliance. ${ }^{10}$ In this study, patients were asked to rate their medicine-taking as 'good' (never miss doses), 'poor' (frequently miss doses) or 'fair' (occassionally miss doses). Tablet counting was not performed, as this is time consuming and will fail to demonstrate under and over-dosing where these occur in equal amounts. ${ }^{10} \mathrm{An}$ alternative method of assessing compliance involves the monitoring of cumulative demands for repeat medicines. In this practice all repeat prescribing is computerised, and many prescriptions are normally requested

\begin{tabular}{|l|}
\hline Brief mental test score \\
\hline - date of birth: one point each for correct date, \\
month and year \\
- date: one point each for day, month and year \\
- age: two points for correct answer, one point if \\
incorrect by only one year \\
- address: one point for correct answer \\
Maximum total score $=9$ points \\
\hline
\end{tabular}

Box 1

Table 1 Medication consumed by study population

\begin{tabular}{|c|c|c|}
\hline Drug category & $\begin{array}{l}\text { No. drugs prescribed to } \\
\text { over } 75 \mathrm{~s}(\%)\end{array}$ & $\begin{array}{l}\text { PACT (\%) (whole practice } \\
\text { population) }\end{array}$ \\
\hline Cardiovascular & $62 \quad(30)$ & 23 \\
\hline CNS & $50 \quad(24)$ & 15 \\
\hline Gastrointestinal & 31 (15) & 9 \\
\hline Respiratory & 19 (9) & 10 \\
\hline Musculoskeletal & $14(7)$ & 6 \\
\hline Infections & 2 (1) & 10 \\
\hline Other & 28 (14) & 27 \\
\hline Total & $206 \quad(100)$ & 100 \\
\hline
\end{tabular}

monthly. It was possible to calculate for each drug, a computer compliance index $c,{ }^{1}$ based on the number of repeats requested over the previous 12 months.

$c=\frac{\text { no of tablets requested and dispensed } \times 100}{\text { no of tablets theoretically required }}$

Quantifying of certain 'as required' medicines, inhalers and topical preparations posed practical difficulties and these were not therefore assessed in this way.

\section{Results}

\section{PATIENT POPULATION}

The practice comprised approximately 5000 patients, $4.5 \%$ of which were aged 75 and over. Hence, the 80 patients interviewed represented one-third of over 75-year-olds. Their mean age was 81.4 years (range 75 to 96 years) with 23 patients $(29 \%)$ aged 85 years and above. Thirty-four patients were male, giving a male to female sex ratio of approximately $3: 4$. Forty-three patients (54\%) were living alone, $28(35 \%)$ with their spouse, and a further nine (11\%) with other family or friends.

\section{MEDICINES TAKEN}

Twenty-one patients (26\%) were taking no prescribed drugs. The other 59 patients were prescribed a total of 206 medicines including $66(32 \%)$ generics. The figure shows the number of drugs taken, with a mean of 2.7 drugs per patient and four being the commonest number of drugs prescribed. This data is very similar to that produced by Cartwright's large descriptive survey. ${ }^{12}$ The mean number of drugs prescribed to men was two, and to women three. This has implications in view of the greater susceptibility of women to adverse drug reactions ${ }^{13}$ and their greater tendency to hoard drugs. ${ }^{4}$

Medicines prescribed were classified as in the British National Formulary except that aspirin was grouped along with analgesic drugs in the central nervous system (CNS) section, and nonsteroidal anti-inflammatory drugs (NSAIDs) with antirheumatic compounds (see table 1). Also shown for comparison is the distribution according to number of drug items prescribed for the whole practice population in the most recent quarterly level one PACT (Prescribing Analysis and Cost) figures, sent by the Prescription Pricing Authority. Relatively more prescriptions were given to the elderly for cardiovascular, CNS (mainly analgesia) and gastrointesinal diseases than for the practice population as a whole.

Table 2 shows the breakdown of specific drug categories. The most widely prescribed drugs were (in decreasing order of frequency) analgesics, diuretics, antacids, glyceryl trinitrate preparations, low-dose aspirin, NSAIDs and laxatives, which accounted for $53 \%$ of total prescribing.

Diuretic drugs were prescribed to $22(28 \%)$ patients (three were taking thiazides, five loop diuretics, five potassium-sparing diuretics, and nine a loop/potassium-sparing combination). This relatively high usage exceeds the $25 \%$ 
level obtained in Cartwright's large survey: ${ }^{12}$ this suggests some inappropriate prescribing, raising the likelihood of known adverse sideeffects such as incontinence, postural hypotension and electrolyte disturbance. ${ }^{2}$ However, only 10 patients (13\%) were taking a NSAID a comparatively low figure. ${ }^{12}$ Increasing awareness of their age-related serious gastrointestinal and renal side-effects ${ }^{14}$ may have prompted

Table 2 Breakdown of drugs prescribed

\begin{tabular}{|c|c|c|c|}
\hline Category & Drug or class & No & Total no (\%) \\
\hline Cardiovascular & $\begin{array}{l}\text { diuretics } \\
\text { glyceryl trinitrate } \\
\text { beta-blockers } \\
\text { digoxin } \\
\text { others }\end{array}$ & $\begin{array}{r}22 \\
13 \\
7 \\
7 \\
13\end{array}$ & $62(30)$ \\
\hline CNS & $\begin{array}{l}\text { paracetamol } \\
\text { other analgesics } \\
\text { low-dose aspirin } \\
\text { tricyclic antidepressants } \\
\text { others }\end{array}$ & $\begin{array}{r}17 \\
12 \\
12 \\
5 \\
4\end{array}$ & $50(24)$ \\
\hline Gastrointestinal & $\begin{array}{l}\text { antacids/alginates } \\
\text { laxatives } \\
\text { cimetidine } \\
\text { other }\end{array}$ & $\begin{array}{r}13 \\
10 \\
6 \\
2\end{array}$ & $31(15)$ \\
\hline Respiratory & $\begin{array}{l}\text { salbutamol preparations } \\
\text { becotide inhalers } \\
\text { aminophylline } \\
\text { others }\end{array}$ & $\begin{array}{l}7 \\
4 \\
4 \\
4\end{array}$ & $19(9)$ \\
\hline Musculoskeletal & $\begin{array}{l}\text { NSAIDs } \\
\text { others }\end{array}$ & $\begin{array}{r}10 \\
4\end{array}$ & $14(7)$ \\
\hline Topical preparations & $\begin{array}{l}\text { eyes (Timoptol 4) } \\
\text { ears/skin }\end{array}$ & $\begin{array}{r}13 \\
2\end{array}$ & $15(7)$ \\
\hline Endocrine & $\begin{array}{l}\text { oral hypoglycaemic drugs } \\
\text { thyroxine } \\
\text { other }\end{array}$ & $\begin{array}{l}4 \\
3 \\
1\end{array}$ & $8(4)$ \\
\hline Miscellaneous & $\begin{array}{l}\text { iron } \\
\text { folic acid } \\
\text { vitamin B12 } \\
\text { Sandocal } \\
\text { tamoxifen } \\
\text { antibiotics }\end{array}$ & $\begin{array}{l}1 \\
1 \\
1 \\
1 \\
1 \\
2\end{array}$ & $7(4)$ \\
\hline
\end{tabular}

Table 3 Consumption of non-prescribed medication

\begin{tabular}{lc}
\hline Medication & No of patients (\%) \\
\hline None & $42(52)$ \\
Paracetamol & $12(15)$ \\
Aspirin & $10(13)$ \\
Laxatives & $7(9)$ \\
Vitamins & $4(5)$ \\
Antacids & $3(4)$ \\
Cod liver oil & $3(4)$ \\
Others & $7(8)$ \\
\hline
\end{tabular}

Table 4 Patients' understanding of their prescribed medication

\begin{tabular}{lcccc}
\hline Understanding & Name correct & Purpose known & Dose/timing correct & Legible labelling \\
\hline Yes & $132(64 \%)$ & $149(72 \%)$ & $155(75 \%)$ & $173(84 \%)$ \\
No & $58(28 \%)$ & $41(20 \%)$ & $31(15 \%)$ & $33(16 \%)$ \\
Partial & $16(8 \%)$ & $16(8 \%)$ & $20(10 \%)$ & - \\
\hline
\end{tabular}

increasing usage of regular paracetamol or other analgesics first (29 patients $(36 \%)$ in this survey). Prescription of sedatives and anxiolytics was noticeably absent, reflecting a policy instituted in this practice some years ago of non-usage and withdrawal where possible of benzodiazepines, in view of their known problems of cognitive impairment, tolerance and dependence. ${ }^{2}$

Analgesics were prescribed twice as commonly to women ( $46 \%$ cases) as to men (24\%). Women were also taking more laxatives and antacids than men. Both sexes were taking similar amounts of diuretics, beta-blockers and other cardiovascular drugs.

\section{SELF-MEDICATION}

Almost half of the patients (38) admitted to taking non-prescribed medicines, compared to only a third found in some previous studies (see table 3$)^{1,8,10}$. A majority $(58 \%)$ of these were taking simple analgesics (paracetamol or aspirin) only occasionally.

Aspirin was only prescribed by the doctors in low dose (eg, $75 \mathrm{mg}$ ) for prevention of transient ischaemic attacks or recurrence of myocardial infarction, not as an analgesic. No relationship was found between the number of prescribed medicines taken and the tendency of the patient to self-medicate.

\section{COMPREHENSION}

Two-thirds of prescribed drugs were correctly named by the elderly (see table 4). Comprehension of the purpose of each medicine was high $(72 \%)$, a similar proportion to that found by Wandless. ${ }^{1}$ Understanding the purpose was greater for certain drugs, eg, analgesics (24 out of 29 drugs) and laxatives (eight out of 10 drugs), and less for others such as diuretics (12 of 22), low-dose aspirin (seven of 12) and cimetidine (two of six). Of the 41 drugs (20\%) where the patients were assessed as having no knowledge, in only 12 cases did they express a wish to learn more about their medicines.

Three-quarters of drug dosage instructions were correctly recalled without reading the label. Of the remaining $25 \%$ ( 51 drugs) where the patient's regimen disagreed with that stated on the label, 20 cases concerned the issue of 'as required' against regular use of analgesics. For the remaining 31 drugs ( $15 \%$ of the total) the dose stated by the patient was incorrect. All labels were typed by computer, and the high level of legibility found ( $84 \%$ ) is encouraging, as this has been shown to be independently related to better compliance. ${ }^{9}$

\section{COMPLIANCE}

The elderly claimed to be 'good' compliers (ie, never miss doses) for $77 \%$ of drugs prescribed

Table 5 Compliance assessment

\begin{tabular}{lclr}
\hline By patient & (no of drugs) & \multicolumn{3}{l}{ By computer } & (no of drugs) \\
\hline Good & $158(77 \%)$ & Correct & $125(80 \%)$ \\
Poor & $7(3 \%)$ & Incorrect & $31(20 \%)$ \\
Fair & $41(20 \%)$ & Not assessed & 50 \\
\hline
\end{tabular}


(see table 5), the same proportion as found in other studies. ${ }^{1,12}$ When compliance according to computer records of repeat prescriptions was analysed, it was found to be inaccurate in $20 \%$ of cases ( 31 drugs). In only 13 of these 31 drugs had the patient admitted 'poor' or 'fair' compliance, indicating a poor correlation between the two methods of assessment. The consequences of non-compliance were judged to be potentially serious or life-threatening for nine of the 31 drugs identified by computer (29\%) but for only four of the 48 drugs $(8 \%)$ based on patient-assessed (non)compliance.

Calculation of the computer compliance index $c$ was performed for the 31 drugs where repeat scripts were being requested too often or infrequently (100 representing perfect compliance). Under-requesting of prescriptions (18 drugs, mean $c=57$ ), was found to be more common than over-requesting ( 13 drugs, mean $c=134$ ). This is consistent with the observation that under-dosing of medicines is the commonest form of non-compliance in the elderly. ${ }^{6,13,15}$

Interestingly, no relationship was found between living alone and compliance, or the number of drugs prescribed and compliance. The mental test score was below the maximum score of nine in only three cases where it was applied (all females in their eighties, two scoring eight and one scoring six). All three ladies knew the correct dosages for their medicines, but the computer confirmed inappropriate requesting of prescriptions for two of them.

There were several cases in this survey where the patient complained of syndromes arising directly from their non-compliance. One man complained of tiredness after halving his dose of thyroxine for no apparent reason. Others included a woman with gritty eyes not taking hypromellose eyedrops regularly, a patient with musculoskeletal pains not taking paracetamol, and one elderly man under blood pressure review after failing to take his medication before a previous consultation. In all these examples, patients knew the correct dose and reasons for taking their medicines, agreed that adequate symptom control was achieved, and yet admitted their aversion to taking drugs. More potentially life-threatening consequences of non-compliance included one woman not taking her cimetidine tablets (prescribed to prevent gastritis and severe recurrent anaemia requiring hospital admission) because she did not know the reason for taking them. Duplica-

Table 6 Differences between patients attending the surgery and group as a whole

\begin{tabular}{lll}
\hline & $\begin{array}{l}\text { Total number interviewed } \\
(80 \text { cases })\end{array}$ & $\begin{array}{l}\text { Patients attending surgery } \\
(17 \text { cases })\end{array}$ \\
\hline Mean age (years) & 81.4 & 79.0 \\
Living alone & $43(54 \%)$ & $6(35 \%)$ \\
On no medication & $20(25 \%)$ & $7(40 \%)$ \\
Mean no drugs prescribed & 2.7 & 1.5 \\
Computer compliance & $125 / 156$ drugs $(80 \%)$ & $23 / 25$ drugs $(92 \%)$ \\
$\quad$ correct & & \\
\hline
\end{tabular}

\begin{tabular}{|l|}
\hline Compliance aids \\
\hline - relation to meals (15) \\
- carer helps (9) \\
- in/out of bed (6) \\
- memory on table (4) \\
- symptoms remind (2) \\
- other (3) \\
\hline
\end{tabular}

Box 2

tion of medicines is also occasionally a problem $^{2}$; one patient in this study was taking coproxamol and paracetamol together inappropriately, and another taking both oxprenolol and Trasicor as she thought that they were different drugs.

\section{INTERVIEW SUBGROUPS}

For those patients interviewed at home, no significant differences were found in the data between patient-initiated and doctor-initiated visits. However, those interviewed whilst attending the surgery for consultation were (perhaps predictably) generally younger, taking few prescribed medicines, and requesting repeat prescriptions at more appropriate intervals (see table 6).

SPECIAL ARRANGEMENTS TO AID COMPLIANCE Over two-thirds of the elderly had adopted strategies to aid their memory regarding drug compliance (box 2). Only three of the elderly possessed memory aid containers, with compartments for each day of the week and different times of the day. Two of these patients actually used them and found them helpful. Although not extensively in use in this practice, they may reduce the omission of drug doses by up to $20 \% .^{7}$ However, they do have the disadvantage of requiring someone to fill them and some elderly people find them difficult to open, resulting in the spilling of contents. $^{5}$

The most popular site for drug storage was the kitchen (usually cabinet or cupboard) (32 patients). A further 15 patients kept their medicines in the living room (on a table or 9 sideboard), six patients favoured the bedroom, and six stored them in other sites.

\section{DIFFICULTIES WITH MEDICATION}

Just over half of those taking regular medicines expressed no difficulty with their administra-

\begin{tabular}{|l|}
\hline Difficulties with medication $(\boldsymbol{n}=\mathbf{8 0})$ \\
\hline - removal of container tops $31 \%$ \\
- difficulty swallowing $8 \%$ \\
- ide-effects limit compliance $8 \%$ \\
- poor taste $3 \%$ \\
- unable to administer eyedrops 3\% \\
- none expressed $54 \%$
\end{tabular}


tion (box 3). The commonest problem was the removal of container tops on drugs; of the 28 patients prescribed an analgesic and/or NSAID, half had difficulty removing the top and three patients had to get someone else to do this for them. Problems were noted both with the commonly used click-lock tops (six cases), and more especially opening a commercially produced branded ethical container (Tracer Packs, eight cases). The latter containers involise the alignment of markings on the side and a degree of force required to open which some elderly arthritic suffers find impossible. Commonly the solution for these patients is to leave the top permanently off the container - hardly in the best interests of drug preservation or child safety. (Interestingly, two patients commented that only their grandchildren were able to remove the tops easily!) It is noteworthy that in the study of Wandless $e t$ $a l^{1}$ carried out prior to the widespread use of child-resistant containers, only two out of 81 patients interviewed had any difficulty removing tablets from their containers.

Four patients were using metered dose inhalers. Two managed with a spacer device; one had excellent and one very poor inhaler technique. The three patients using Rotacaps managed satisfactorily. Three of the elderly were prescribed both salbutamol and Becotide, only one of whom was aware of the prophylactic rationale behind regular inhaled corticosteroids.

\section{Discussion}

As in many surveys, important questions are raised by the observations rather than any firm conclusions being reached. Inaccuracy and bias may have been introduced by the relatively small sample size, the recruitment of patients from several sources, and the exclusion of nursing and residential home patients. In the case of doctor-initiated home visits, those who were not found at home on three separate occasions were also excluded. Nevertheless, it is reassuring that the relatively high degree of knowledge and understanding by the elderly regarding their drugs confirms previous research. ${ }^{1,4,12}$ Although the mean of 2.7 drugs per patient in this practice represents a typical level of prescribing, 31 patients $(39 \%)$ are still taking four or more medicines, a level at which compliance problems can start to occur even in the average alert over-75-year-old. ${ }^{3,7,15}$

The figure of $80 \%$ accuracy of patient compliance based on computer repeat prescription records may well be an overestimate for several reasons. Grossly inappropriate early or very late repeat requests are queried by the practice dispenser and referred to the doctors. Erratic taking of medicines also remains

1 Wandless I, Mucklow JC, Smith A, Prudham D. Compliance with prescribed medicines: a study of elderly pliance with prescribed medicines: a study of elderly patients

2 Anon. Elderly people: their medicines and their doctors. Anon. Elderly people: their medic

3 Coni N, Darron W, Webster S. Medical and surgical 3 Coni N, Darron W, Webster S. Medical and surgical
treatment of the old. In: Lecture notes on geriatrics 3rd edn treatment of the old. In: Lecture notes
Oxford: Blackwell, 1988; pp 219-28.

\section{Key points}

- the majority of elderly patients understand and adhere to their drug regimes

- many of those interviewed remembered their medication by building tablet taking into their daily activities

- medicine containers are difficult to open, especially for those patients taking analgesic or anti-inflammatory drugs

- most patients do not realise that they have the option of requesting non-child-resistant containers from their doctor or pharmacist

- computer records can be valuable when assessing drug compliance in primary care

- every practice should develop its own mechanism for reviewing elderly prescriptions, and consider an audit of such prescribing at regular intervals

Box 4

undetected. Conversely (as two patients commented), a monthly repeat prescription helps to remind some people to take their medication.

The finding that nearly one third of patients on medication (and half of those on analgesics, presumably mainly for osteoarthritis) had difficulty in removing container tops is cause for concern. The pharmacist or doctor (who must otherwise legally dispense a child-resistant container) would probably be wise to ask the elderly about container preference. In addition, it has been previously recommended that these should be made of transparent glass or plastic ${ }^{5,6}$ as many elderly recognise tablets by their shape or colour. A large 'palm-sized' bottle with an ordinary screw top, kept out of reach of children, may be the most practical solution.

Adherence to drug therapy can diminish with time, along with the closeness of monitoring by the patient's general practitioner. Rationalisation of treatment and prompt removal of out-of-date or inappropriate medicines from patient's homes should be part of routine good medical practice when visiting the elderly. Patients also have an ethical and legal right to information about the medicines they are taking, including side-effects. ${ }^{11}$ Hopefully the obligation of the 1990 General Practitioner Contract to offer the over-75-year-olds annual health checks, including a review of medication, together with the extending roles of pharmacists and community nurses, will continue to improve drug compliance and comprehension in the elderly.

I am grateful to Drs DJ Belbin, WH Smithson and S McWhinney, and all the staff at Escrick Surgery, York, for their valuable assistance and cooperation with this project.

4 Law $R$ Chalmers $C$ Medicines and elderly people: general practice survey. $B M 7$ 1976; 1: $565-8$

5 Medication for the elderly - a report of the Royal College of Physicians. $\mathcal{F} R$ Coll Physicians Lond 1984; 18: 7-17.

6 Van der Cammen TJM, Rai GS, Exton-Smith AN. Handling of drugs and implications for prescribing. In Manual of geriatric medicine, 1st edn. Edinburgh: Longman, $1991 ; 283-9$ 
7 Anderson F, Williams B. Sensible prescribing. In: Practical management of the elderly 5th edn. Oxford: Blackwell, 1989, vol 4, pp 45-7.

8 Lowe CJ, Raynor DK, Courtney EA, Purvis J, Teale C. Effect of self medication programme on knowledge and compliance with treatment in elderly patients. $B M \mathcal{F} 1995$ 310: $1229-31$.

9 Lorenc L, Branthwaite A. Are older adults less compliant with prescribed medication than younger adults? $\mathrm{Br} \mathcal{F}$ Clin Psychol 1993; 32: 485-92.

10 Davie JW, Wandless I. Improving drug compliance in the elderly. In: Caird FI, Grimley Evans J, eds, Advanced elderly. In: Caird FI, Grimley Evans J, eds, Advanced

11 Anon. Helping patients to make best use of medicines. Drug Ther Bull 1991; 29: no 1.
12 Cartwright A, Smith C. Elderly people: their medicines and their doctors. London: Routledge, 1988

13 O'Malley K, Meagher F. Pharmacological aspects of therapeutics. In: Exton-Smith N, Wekster ME, eds, Practical geriatric medicine. Edinburgh: Churchill Livingstone, 1985; pp 51-6.

14 Kirchner JT. Nonsteroidal anti-inflammatory drug use in the elderly: issues of compliance and safety (review). $\mathcal{f} \mathrm{Am}$ Osteopathic Assoc 1994; 94: 300-4.

15 Salzman C. Medication compliance in the elderly (review). f Clin Psychiatry 1995; 56(suppl 1): 18-23. 